\title{
Reconfigurable Single-/Dual-Wideband Bandpass Filters Based on a Novel Topology
}

\author{
Xiaokun Bi ${ }^{1,2}$, Shaohua Guo ${ }^{3}$, Zengpei Zhong ${ }^{1,2}$, Kaidong Hong ${ }^{1,2}$, Wei He ${ }^{4, *}$ \\ and Tao Yuan 1,2,5,* \\ 1 Guangdong Provincial Mobile Terminal Microwave and Millimeter-Wave Antenna Engineering Research \\ Center, College of Electronics and Information Engineering, Shenzhen University, Shenzhen 518060, China; \\ xiaokun.bi@barrot.com.cn (X.B.); zhongzengpei2016@email.szu.edu.cn (Z.Z.); \\ 2170269112@email.szu.edu.cn (K.H.) \\ 2 Greater Bay Area Joint Laboratory of Big Data Imaging and Communication, Shenzhen 518048, China \\ 3 School of Water Conservancy and Environment, Zhengzhou University, Zhengzhou 450001, China; \\ yb57427@umac.mo \\ 4 China Academy of Information and Communications Technology, Beijing 100191, China \\ 5 ATR National Key Laboratory of Defense Technology, Shenzhen University, Shenzhen 518060, China \\ * Correspondence: hewei3@caict.ac.cn (W.H.); yuantao@szu.edu.cn (T.Y.)
}

Received: 29 October 2020; Accepted: 11 December 2020; Published: 15 December 2020

\begin{abstract}
Based on a new topology, a series of single-/dual-wideband bandpass filters (SWB/DWB $\mathrm{BPFs})$ with reconfigurable masses of properties are presented. The proposed design starts from a dual-wideband passive filtering structure, which owns five transmission zeros in the stopbands and three transmission poles in each passband. Then, three capacitors are employed as the tuning elements. By controlling these three capacitors, DWB BPFs with different reconfigurable properties, including three independently tunable passband edges, tunable center frequency of lower passband with fixed absolute bandwidth, tunable bandwidth of lower passband with fixed center frequency, and switchable lower passband, can be realized. In addition, SWB BPF with tunable bandwidth also can be achieved by varying the inserted capacitors. For verification, a prototype with different capacitors is designed and fabricated. As the measured and simulated results agree well with each other, a simple design approach of reconfigurable SWB/DWB BPFs can be verified.
\end{abstract}

Keywords: single-/dual wideband; bandpass filter; tunable bandwidths; tunable center frequency; switchable passband

\section{Introduction}

In the high-data telecommunication systems, single-/dual-wideband bandpass filters (SWB/DWB BPFs) with compact size and good responses play an important role, and various approaches have been proposed for such filters [1-5]. For example, SWB BPF without reflection can be designed by using multilayered substrate [2]. Meanwhile, DWB BPF with a controllable stopband has been designed based on terminated multi-mode resonator [4]. Although all the desired responses can be achieved in the above filters, they still could not satisfy the requirements of modern multi-service wireless systems, which need filters with different reconfigurable properties to reduce the design complexity, cost, and size.

Early developments in reconfigurable BPFs mainly focused on center-frequency tuning [6-10]. For example, the center frequency of a four-pole SWB BPF can be varied from $1.05 \mathrm{GHz}$ to $1.40 \mathrm{GHz}$ while its corresponding absolute bandwidth is fixed about $134.5 \mathrm{MHz}$ [8]. However, little effort has been devoted to DWB ones with fixed absolute bandwidths. Later, research on the switchable passbands 
and tunable bandwidths were added [11-23]. Compared to SWB BPFs with tunable bandwidth [11-14] and dual-band BPFs with switchable passbands [15-17], much less efforts have been devoted to DWB ones with tunable bandwidths, and only six IEEE journal papers have been reported [18-23]. As the tunable-bandwidth filters in [18-20] are based on in-parallel BPF cascades, some drawbacks, i.e., small bandwidth and tuning ranges, and limited center frequency ratio, exists. To tackle these, an alternative method based on one transmission path is proposed [21-23]. However, some tunable properties, such as independently tunable bandwidth of lower passband with fixed center frequency, have never been reported. In addition, no more than two passband edges can be tunable independently in a reported DWB BPF. The lack of study on DWB BPFs with tunable band- widths will largely restrict the development of modern telecommunication. Therefore, it is very important to explore novel topologies, whose aim is to design SWB/DWB BPFs with new and numerous reconfigurable properties in designing advanced transceivers for practical applications of high-performance systems effectively and conveniently.

In this paper, a novel topology for the design of SWB/DWB BPFs with masses of reconfigurable properties is proposed. The novel topology is based on a DWB passive filtering structure, which is formed by a T-shaped resonator with two parallel-coupled lines (PCLs) and three open-ended stubs. After theoretically analyzing, it is found that the passive filtering structure owns three transmission poles (TPs) in each passband and five transmission zeros (TZs) in the stopbands. Three capacitors are then inserted as the tuning elements. By controlling the inserted elements, it is found that three passband edges can be independently tunable. In addition, other reconfigurable properties, i.e., tunable center frequency of lower passband with fixed absolute bandwidth, tunable bandwidth of lower passband with fixed center frequency, and switchable lower passband, can be directly derived. Furthermore, SWB BPFs with independently tunable first passband edge can also be designed by using the proposed topology. To verify these, a prototype with different capacitors is designed and measured. To the best of the authors' knowledge, a single prototype, which can achieve SWB BPFs with tunable bandwidth, and DWB BPFs with tunable bandwidths, tunable center frequency, and switchable passband simultaneously, has never been reported before.

Except for the introduction in Section 1, the discussions of proposed topology with emphasis on TP/TZ analysis and reconfigurable properties are presented in Section 2. In Section 3, the design and implementation of the reconfigurable SWB/DWB BPFs are illustrated with the comparison with the simulated and experimentally measured results. A conclusion is summarized in Section 4.

\section{Operation Principle and Design}

As shown in Figure 1, the novel topology is composed of a passive filtering structure with three capacitors. The passive filtering structure starts from a terminated T-shaped resonator with open terminations, whose characteristic impedances and electrical length are $Z_{3}, Z_{2}, Z_{3}$, and $\theta=\pi / 2$ at the operating frequency $f_{0}$, respectively. Thus, its input impedance can be written as

$$
Z_{\text {in }}^{T}=j Z_{2} \frac{2 Z_{2} \tan ^{2} \theta-Z_{3}}{\left(2 Z_{2}+Z_{3}\right) \tan \theta}
$$

Based on (1), it is apparent that the T-shaped resonator owns a pole $f_{p 1}^{T}$ and two zeros of $f_{z 1}^{T}, f_{z 2}^{T}$. For arbitrary $Z_{2}$ and $Z_{3}$, the relationship of $f_{z 1}^{T}<f_{p 1}^{T}=f_{0}<f_{z 2}^{T}$ exists. To incorporate it for a dual-band BPF with good filtering responses, extra poles and zeros should be introduced, while the intrinsic pole of $f_{p 1}^{T}$ must be eliminated. Therefore, a pair of PCLs and three shunt open-ended stubs are added. The parameters of $Z_{o e}, Z_{o o}$, and $\theta$ present the characteristic impedances and electrical length of PCLs, while $Z_{1}, Z_{4}, Z_{1}$, and $\theta_{L}, \theta, \theta_{R}$ denote those of the added stubs, where $\theta_{L}=\theta_{1}+\theta_{2}$, and $\theta_{R}=\theta_{1}+\theta_{3}$. 


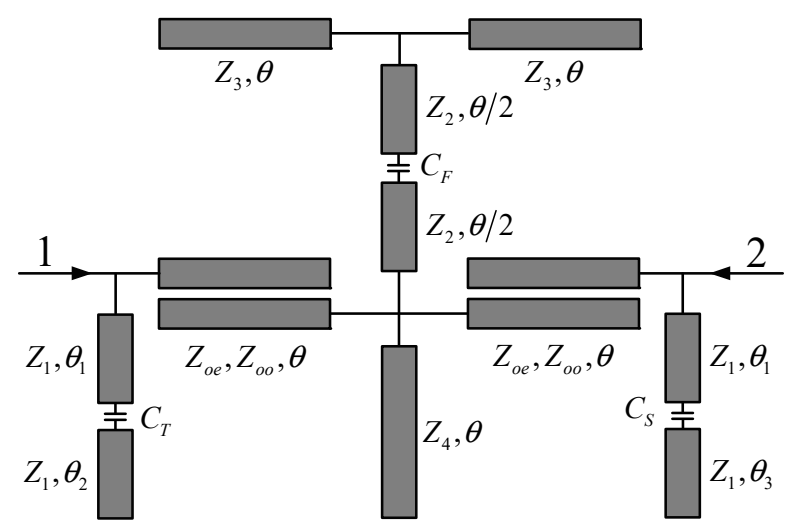

Figure 1. The novel topology for the proposed filters $\left(\theta_{L}=\theta_{1}+\theta_{2}, \theta_{R}=\theta_{1}+\theta_{3}\right)$.

\subsection{Transmission Poles and Zeros}

To simplify the theoretical analysis, we assume $\theta_{L}=\theta_{R}=\theta$ at first. Under this condition, the passive filtering structure is symmetrical. Hence, its TPs can be determined by using even-odd-mode analysis method. Figure 2 depicts the odd- and even-mode equivalent circuits. After analyzing the odd-mode equivalent circuit in Figure 2a, its input admittance can be written as

$$
Y_{\text {ino }}=\frac{2 j A \tan \theta}{\left(A^{2}-B^{2}\right)-B^{2} \tan ^{2} \theta}+j \frac{1}{Z_{1}} \tan \theta
$$

where

$$
\begin{gathered}
A=Z_{o e}+Z_{o o} \\
B=Z_{o e}-Z_{o o}
\end{gathered}
$$

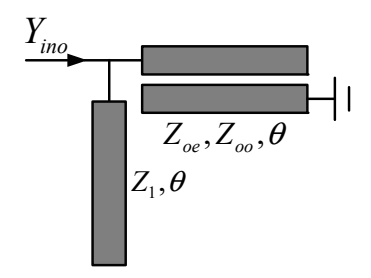

(a)

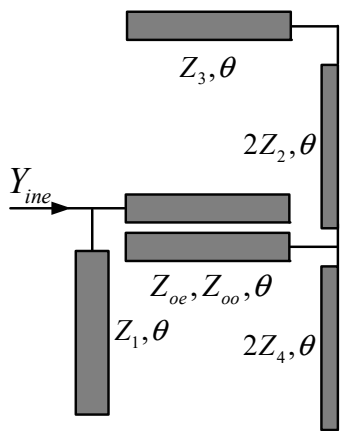

(b)

Figure 2. (a) Odd- and (b) even-mode equivalent circuits $\left(\theta_{L}=\theta_{R}=\theta\right)$.

Under the condition that $Y_{\text {ino }}$ is zero, two odd-mode resonant frequencies can be determined as

$$
\begin{aligned}
& f_{o p 1}=f_{0}-\frac{2 f_{0}}{\pi} \arctan \left(\sqrt{\frac{A^{2}-B^{2}+2 A Z_{1}}{B^{2}}}\right) \\
& f_{o p 2}=f_{0}+\frac{2 f_{0}}{\pi} \arctan \left(\sqrt{\frac{A^{2}-B^{2}+2 A Z_{1}}{B^{2}}}\right)
\end{aligned}
$$


For the even-mode equivalent circuit in Figure $2 b$, its input admittance can be expressed as

$$
Y_{\text {ine }}=j \frac{1}{Z_{1}} \tan \theta+\frac{2 Y_{L} A \tan \theta+4 j \tan ^{2} \theta}{2 A \tan \theta+j Y_{R}\left(B^{2} \tan ^{2} \theta+B^{2}-A^{2}\right)}
$$

where

$$
Y_{R}=j \frac{1}{2 Z_{4}} \tan \theta+\frac{1}{2 Z_{i n}^{T}}
$$

When $Y_{\text {ine }}$ is zero, two pairs of even-mode resonant frequencies can be obtained as

$$
\begin{aligned}
& f_{e p 1}=f_{0}-\frac{2 f_{0}}{\pi} \arctan \sqrt{\frac{\Delta_{2}+\sqrt{\Delta_{2}^{2}-4 \Delta_{1} \Delta_{3}}}{2 \Delta_{1}}} \\
& f_{e p 2}=f_{0}-\frac{2 f_{0}}{\pi} \arctan \sqrt{\frac{\Delta_{2}-\sqrt{\Delta_{2}^{2}-4 \Delta_{1} \Delta_{3}}}{2 \Delta_{1}}} \\
& f_{e p 3}=f_{0}+\frac{2 f_{0}}{\pi} \arctan \sqrt{\frac{\Delta_{2}-\sqrt{\Delta_{2}^{2}-4 \Delta_{1} \Delta_{3}}}{2 \Delta_{1}}} \\
& f_{e p 4}=f_{0}+\frac{2 f_{0}}{\pi} \arctan \sqrt{\frac{\Delta_{2}+\sqrt{\Delta_{2}^{2}-4 \Delta_{1} \Delta_{3}}}{2 \Delta_{1}}}
\end{aligned}
$$

where

$$
\begin{gathered}
\Delta_{1}=Z_{2}^{2} B^{2} \\
\Delta_{2}=2 Z_{2}^{2}\left(4 A Z_{4}+2 A Z_{1}+8 Z_{4}+A^{2}-B^{2}\right)+B^{2}\left(Z_{2} Z_{3}+Z_{3} Z_{4}+4 Z_{2} Z_{4}\right) \\
\Delta_{3}=\left(Z_{2} Z_{3}+Z_{3} Z_{4}+4 Z_{2} Z_{4}\right)\left(2 A Z_{1}+A^{2}-B^{2}\right)+4 Z_{2} Z_{3} Z_{4}\left(A+2 Z_{1}\right)
\end{gathered}
$$

To achieve sharp skirt selectivity and ensure high isolation levels, TZs are essential. For this topology, its TZs can be determined by using even-odd-mode analysis method and S-parameters theory together. The transmission coefficient $S_{21}$ can be written as

$$
S_{21}=\frac{Y_{0}\left(Y_{\text {ine }}-Y_{\text {ino }}\right)}{\left(Y_{\text {ino }}+Y_{0}\right)\left(Y_{\text {ine }}+Y_{0}\right)}
$$

After some algebraic operations, three TZs can be obtained and written as

$$
\begin{gathered}
f_{z 1}=\frac{2 f_{0}}{\pi} \arctan \left(\sqrt{\frac{Z_{3}}{2 Z_{2}}}\right) \\
f_{z 2}=f_{0} \\
f_{z 3}=2 f_{0}-\frac{2 f_{0}}{\pi} \arctan \left(\sqrt{\frac{Z_{3}}{2 Z_{2}}}\right)
\end{gathered}
$$

It is apparent that the passive filtering structure owns six TPs and three TZs when $\theta_{L}=\theta_{R}=\theta$, and all the TPs and TZs are symmetrical to $f_{0}$. In addition, the relationships of $f_{z 1}<f_{\text {ep } 1}<f_{\text {op } 1}<$ $f_{e p 2}<f_{z 2}=f_{0}<f_{e p 3}<f_{o p 2}<f_{e p 4}<f_{z 3}$ always hold for arbitrary $Z_{1}, Z_{o e}, Z_{o o}, Z_{2}, Z_{3}$, and $Z_{4}$. Hence, the proposed topology is suitable to design triple-mode DWB BPFs. Furthermore, the filter bandwidths are mainly controlled by the locations of $f_{e p 1,2,3,4}$, while the skirt selectivity near the first and fourth passband edges are mainly determined by those of $f_{z 1}$ and $f_{z 2}$. To better understand this, TPs/TZs with respect to different characteristic impedances of $Z_{1}, Z_{2}, Z_{3}, Z_{4}, Z_{o o}$, and $Z_{o e}$, are shown in Figure 3 . 
Obviously, the locations of $f_{e p 1}$ and $f_{e p 4}$ are sensitive to $Z_{2}$ and $Z_{3}$, while the locations of $f_{e p 2}$ and $f_{e p 3}$ are mainly determined by $Z_{o o}$ and $Z_{o e}$. Reflected to filter responses, the first and fourth passband edges will move closer to each other as $Z_{2}$ decreases or $Z_{3}$ increases, and the second and third ones will move apart as $Z_{o o}$ decreases or $Z_{o e}$ increases. Hence, a filter with a wide bandwidth should own large $Z_{2}$ and small $Z_{3}$, while a filter with a large center frequency ratio need choose small $Z_{o o}$ and large $Z_{o e}$. For the rest of the parameters, they are used to ensure good matching in each passband and sharp skirt near the first and fourth passband edges.

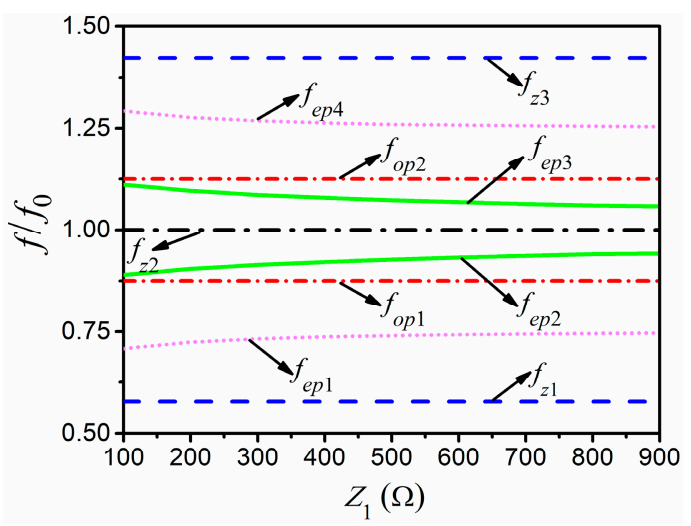

(a)

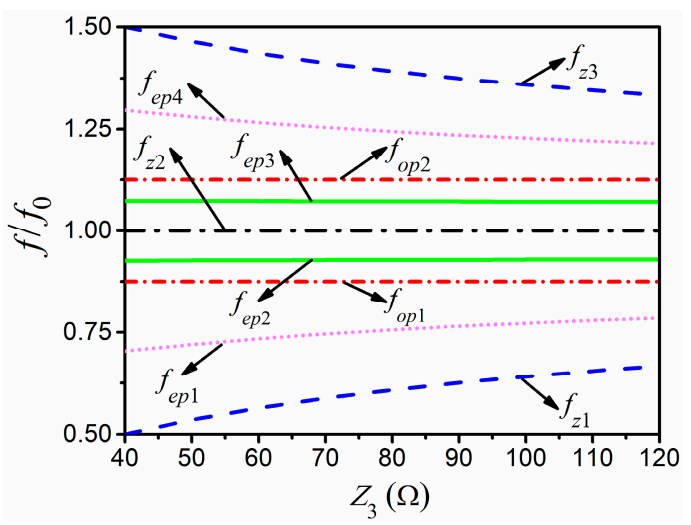

(c)

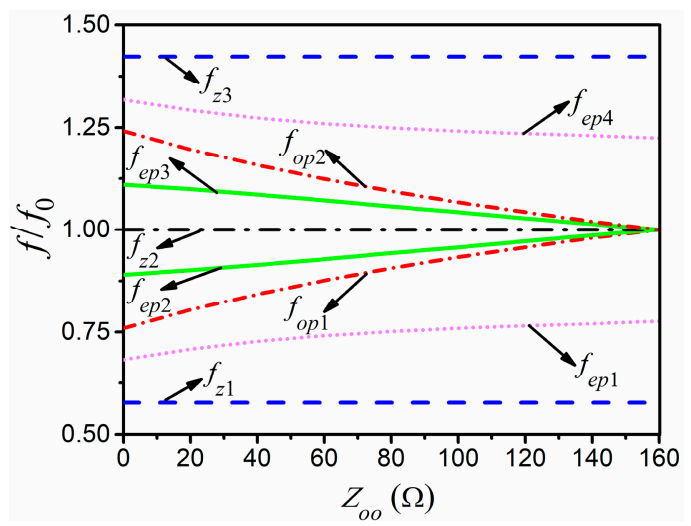

(e)

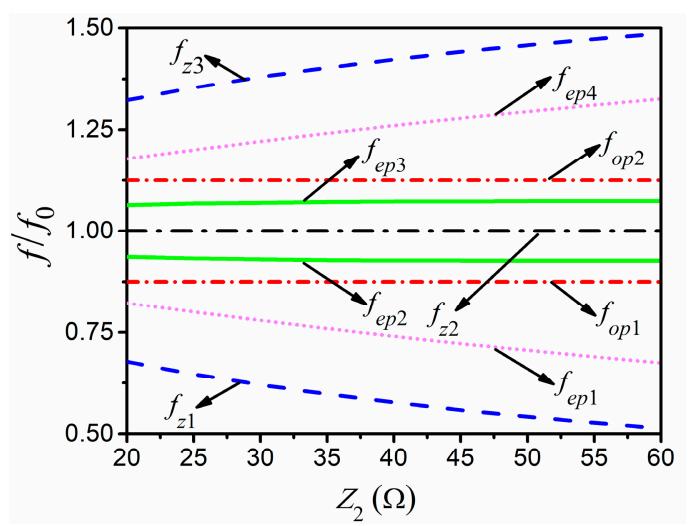

(b)

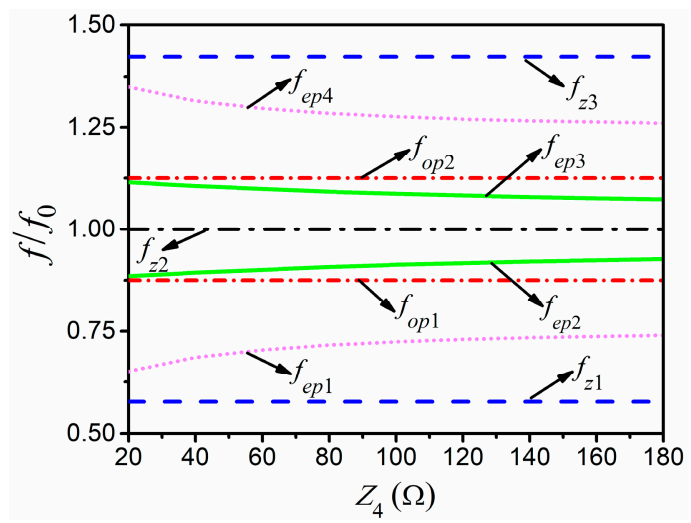

(d)

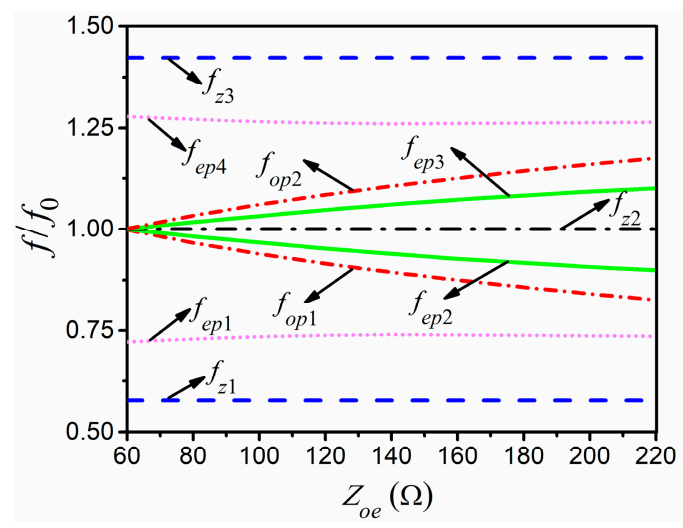

(f)

Figure 3. Transmission poles/ transmission zeros (TPs/TZs) with respect to varied characteristic impedances of (a) $Z_{1}$; (b) $Z_{2}$; (c) $Z_{3}$; (d) $Z_{4}$; (e) $Z_{o o}$; (f) $Z_{o e}$ (The reference parameters are: $Z_{1}=500 \Omega$, $\left.Z_{2}=40 \Omega, Z_{3}=80 \Omega, Z_{4}=160 \Omega, Z_{o o}=63 \Omega, Z_{o e}=160 \Omega\right)$. 
Due to the lack of TZs near the second and third passband edges, the corresponding selectivity is poor under the condition that $\theta_{L}=\theta_{R}=\theta$. To deal with this, the electrical length of $\theta_{L}$ and $\theta_{R}$ should be studied. To better demonstrate these, a revised topology for the theoretical analysis is shown in Figure 4. First of all, $\Delta \theta=1.11\left(\theta-\theta_{L}\right)=\theta_{R}-\theta$. When $\Delta \theta$ is zero, there is only one TZ between passbands, as analyzed above. As $\Delta \theta$ increases, another two TZs of $f_{I 1}$ and $f_{I 2}$ are introduced and move apart gradually. Meanwhile, TPs of $f_{e p 2,3}$ and $f_{o p 1,2}$ move apart slightly. For the rest of the TPs/TZs, they are maintained unaltered, as shown in Figure 5. Hence, the skirt selectivity of the passive filtering structure near the second and third passband edges can be improved by generating TZs of $f_{I 1}$ and $f_{I 2}$ through suitably choosing $\theta_{L}$ and $\theta_{R}$. Furthermore, the relationships among $f_{I 1}, f_{I 2}, \theta_{L}$, and $\theta_{R}$ can be approximately obtained as

$$
\begin{aligned}
& f_{I 1} \approx \frac{\pi}{2 \theta_{R}} f_{0} \\
& f_{I 2} \approx \frac{\pi}{2 \theta_{L}} f_{0}
\end{aligned}
$$

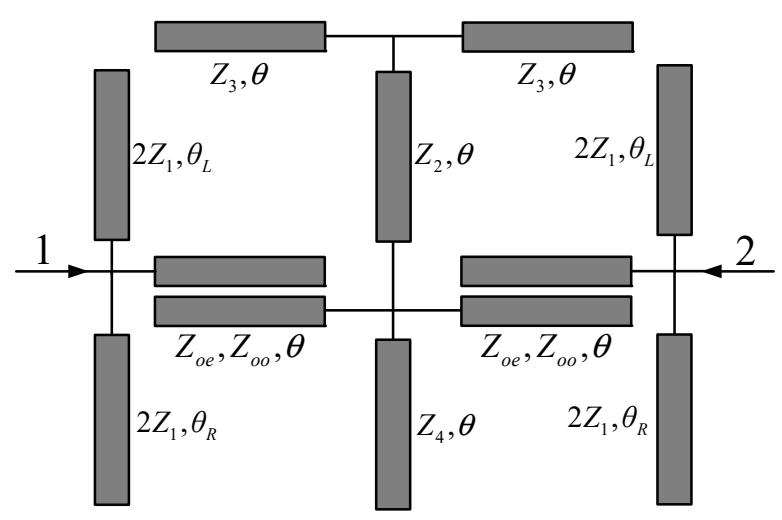

Figure 4. The revised topology for theoretical analysis $\left(\theta_{L}=\theta_{1}+\theta_{2}, \theta_{R}=\theta_{1}+\theta_{3}\right)$.

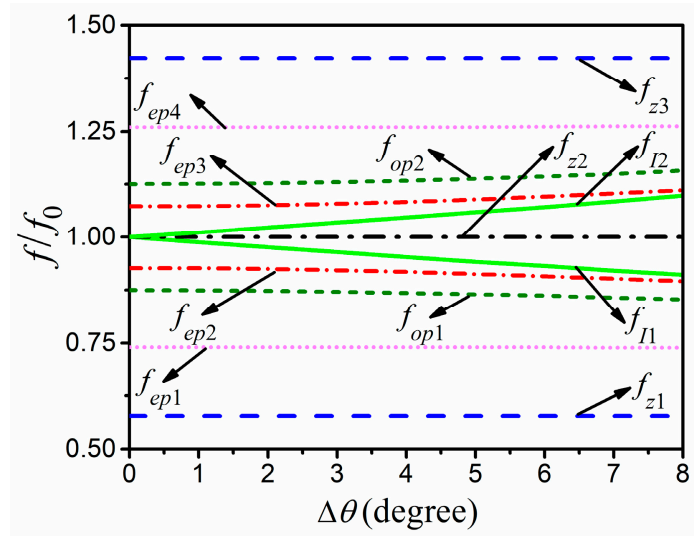

Figure 5. TPs and TZs with respect to different $\Delta \theta$.

One thing should be noted: whatever the electrical lengths of $\theta_{L}$ and $\theta_{R}$ are, the relationships of $f_{z 1}<f_{e p 1}<f_{o p 1}<f_{e p 2}<f_{I 1}<f_{z 2}=f_{0}<f_{I 2}<f_{e p 3}<f_{o p 2}<f_{e p 4}<f_{z 3}$ always exist. Hence, the second and third passband edges can be independently controlled by varying $\theta_{L}$ and $\theta_{R}$, as the ones in $[4,23]$.

\subsection{Reconfigurable Properties}

To realize the desired reconfigurable properties, some tuning elements should be inserted into the passive filtering structure. At first, a lumped capacitor $C_{F}$ is employed as one of the tuning elements, 
which is located at the middle of the lower stub of T-shaped resonator with open terminations. Under this condition, the input impedance of T-shaped resonator with capacitor $C_{F}$ can be expressed as

$$
Z_{i n_{-} C_{F}}^{T}=Z_{2} \frac{Z_{\text {in } 1}+j Z_{2} \tan (\theta / 2)}{Z_{2}+j Z_{\text {in } 1} \tan (\theta / 2)}
$$

where

$$
Z_{i n 1}=j Z_{2} \frac{Z_{3} \tan \theta+2 Z_{2} \tan (\theta / 2)}{2 Z_{2}-Z_{3} \tan (\theta / 2) \tan \theta}+\frac{1}{j \omega C_{F}}
$$

If the inserted capacitor $C_{F}$ is large enough, the input impedance of T-shaped resonator with capacitor can be simplified to the one without capacitor. Under this condition, the effect of the inserted capacitor on the filter responses is insignificant. With the decrease in $C_{F}$, however, the conditions are changed, and the effect of the inserted capacitor $C_{F}$ on $f_{e p 1}$ is much larger than the ones on $f_{e p 2}, f_{e p 3}, f_{e p 4}$. Reflected to the filter responses, the first passband edge can be independently tunable by altering $C_{F}$, while the other three are fixed, as illustrated in Figure $6 \mathrm{a}$, where the 3-dB passband edges with TZs for sharp selectivity are depicted with respect to different $C_{F}$.

As mentioned in Part $\mathrm{A}$, the second and third passband edges can be independently controlled by varying $\theta_{L}$ and $\theta_{R}$. Hence, the other two capacitors of $C_{S}$ and $C_{T}$ are then inserted into the open- ended stubs with $Z_{1}$ for independent tunabilities of these two passband edges. In Figure $6 \mathrm{~b}, \mathrm{c}, 3-\mathrm{dB}$ passband edges with TZs for sharp selectivity with respect to different capacitors of $C_{S}$ and $C_{T}$ are depicted. Apparently, these two passbands also can be independently tunable by controlling the capacitors of $C_{S}$ and $C_{T}$, respectively.

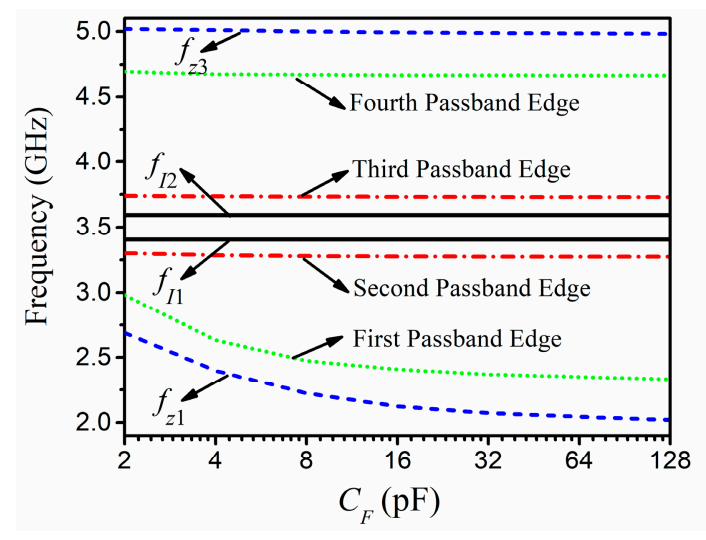

(a)

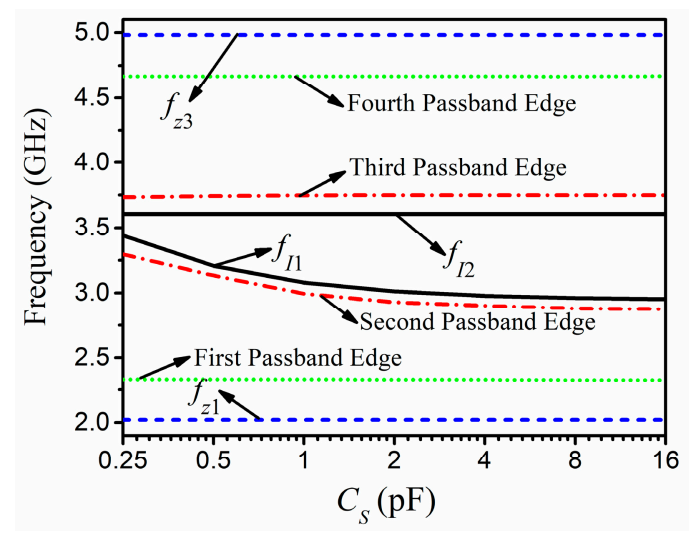

(b)

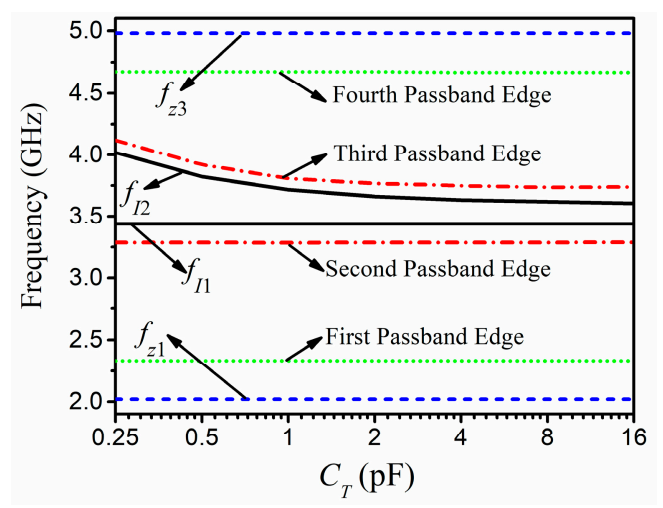

(c)

Figure 6. 3-dB passband edges with TZs for sharp skirt with respect to different $(\mathbf{a}) C_{F} ;(\mathbf{b}) C_{S} ;(\mathbf{c}) C_{T}$. 
According to the theoretical analysis mentioned above, the first and second passband edges can be independently tunable. Thus, the reconfigurable properties, i.e., independently tunable center frequency of lower passband with fixed absolute bandwidth, and independently tunable bandwidth of lower passband with fixed center frequency, can be directly realized by suitably selecting the capacitors of $C_{F}$ and $C_{S}$. Furthermore, it is interesting that the lower passband will disappear when $C_{F}$ is small and $C_{S}$ is large enough. Hence, the switchable lower passband also can be achieved. As the third passband edge is independently controlled by the capacitor of $C_{T}$, a SWB BPF with tunable bandwidth can be designed too. For verification, a prototype with different capacitors is designed and measured, which will be presented in detail in Section 3.

\section{Design Examples}

Based on the theory in Section 2, a simple and effective design procedure for the desired prototype can be concluded as:

(1) On the basis of DWB BPF with the widest bandwidth, initially determine the design para-meters of the passive filtering structure, i.e., $Z_{1}, Z_{2}, Z_{3}, Z_{4}, Z_{o o}, Z_{o e}, \theta_{1}, \theta_{2}$, and $\theta_{3}$.

(2) Based on the different locations of first and third passband edges, determine $C_{F}$ and $C_{T}$.

(3) Based on the various locations of second passband edge, determine $C_{S}$ and $\theta_{3}$.

(4) After slightly optimizing, obtain the final parameters.

On the basis of the above procedure, the design parameters of a reconfigurable DWB BPF with widest fractional bandwidths (FBWs) of $25.7 \%, 17.5 \%$, and center frequencies (CFs) of $2.82 \mathrm{GHz}$ and $4.12 \mathrm{GHz}$ can be concluded as: $Z_{1}=500 \Omega, Z_{2}=40 \Omega, Z_{3}=80 \Omega, Z_{4}=160 \Omega, Z_{o o}=63 \Omega$, $Z_{o e}=160 \Omega, \theta_{1}=40^{\circ}, \theta_{2}=47.6^{\circ}, \theta_{3}=54.2^{\circ}, C_{F}=C_{T}=100 \mathrm{pF}, C_{S}=2.4 \mathrm{pF}$, and $f_{0}=3.47 \mathrm{GHz}$. Then, the reconfigurable properties can be achieved by only changing the inserted capacitors. As the fabricated filter is implemented on Rogers RO4003B with dielectric constant of $3.38 \mathrm{~mm}$ and thickness of 0.813 $\mathrm{mm}$, its dimensions and layout can be determined with the aid of commercial software, as shown in Figure 7. In this layout, a design skill is used: to enlarge the equivalent value of $Z_{1}$ and enhance the coupling strength of PCLs, some parts of the open-ended stubs with $Z_{1}$ are parallel to PCLs.

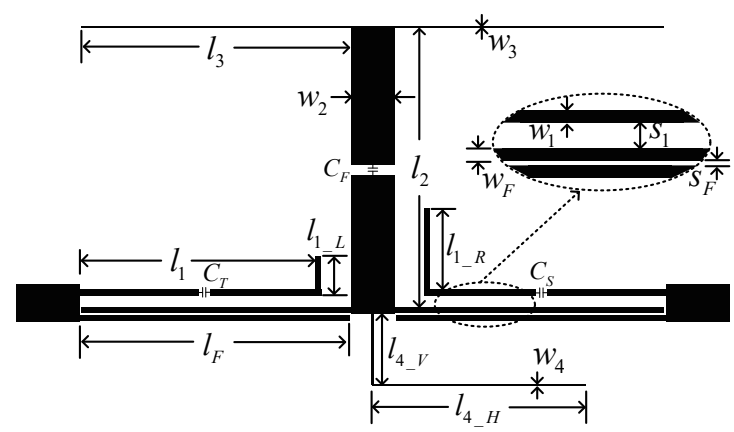

Figure 7. Layout of the fabricated filter $\left(l_{1}=12.2 \mathrm{~mm}, l_{1 \_L}=2.05 \mathrm{~mm}, l_{1 \_R}=4.35 \mathrm{~mm}, w_{1}=0.3 \mathrm{~mm}\right.$, $s_{1}=0.5 \mathrm{~mm}, l_{F}=13.6 \mathrm{~mm}, w_{F}=0.3 \mathrm{~mm}, s_{F}=0.1 \mathrm{~mm}, l_{2}=13.75 \mathrm{~mm}, w_{2}=2.4 \mathrm{~mm}, l_{3}=13.4 \mathrm{~mm}$, $\left.w_{3}=0.1 \mathrm{~mm}, l_{4 \_V}=3.6 \mathrm{~mm}, l_{4 \_H}=10.8 \mathrm{~mm}, w_{4}=0.1 \mathrm{~mm}\right)$.

The filtering responses under different cases are measured by a Keysight N5224A network analyzer. For Case A with $C_{F}=C_{T}=100 \mathrm{pF}$, and $C_{S}=2.4 \mathrm{pF}$, the corresponding measured results are plotted with the simulated ones in Figure 8. Apparently, they agree well with each other, except for some slight discrepancies, which are caused by the fabrication and measured tolerances. Under the condition that the matching is better than $10.0 \mathrm{~dB}$, the measured FBWs are $26.6 \%, 17.8 \%$ with $\mathrm{CFs}$ of $2.82 \mathrm{GHz}$ and $4.10 \mathrm{GHz}$ for the first and second passbands, respectively. In addition, over 20-dB insertion loss can be found in the stopband between two passbands from $3.33 \mathrm{GHz}$ to $3.63 \mathrm{GHz}$, indicating high isolation level. Five TPs for good flatness in the passbands are found at $2.52 \mathrm{GHz}, 2.90 \mathrm{GHz}, 3.12 \mathrm{GHz}$, 
3.80 GHz, and $4.30 \mathrm{GHz}$, respectively, while five TZs for sharp skirt and high isolation levels are located at $2.12 \mathrm{GHz}, 3.34 \mathrm{GHz}, 3.46 \mathrm{GHz}, 3.59 \mathrm{GHz}$, and $4.88 \mathrm{GHz}$. In addition, the group delay within two passbands is no more than $1.78 \mathrm{~ns}$. The overall size of the fabricated filter is $36.0 \times 25.0 \mathrm{~mm}$.

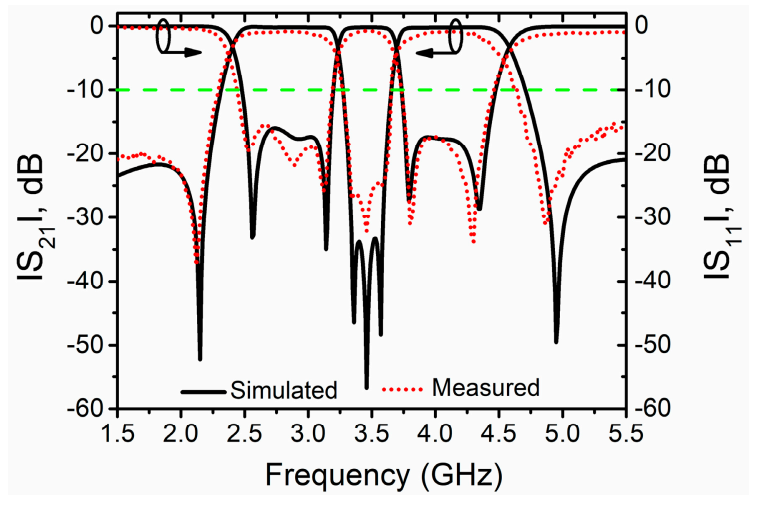

Figure 8. Filter responses of Case $\mathrm{A}\left(C_{F}=100 \mathrm{pF}, C_{S}=2.4 \mathrm{pF}, C_{T}=100 \mathrm{pF}\right)$.

\subsection{Three Independently Tunable Passband Edges}

The simulated and measured $S$-parameters of Case B with $C_{F}=4.7 \mathrm{pF}, C_{S}=2.4 \mathrm{pF}$, and $C_{T}=100 \mathrm{pF}$ are shown in Figure 9a. By comparing Case A and B, it is apparent that the first passband edge with matching better than $10.0 \mathrm{~dB}$ can independently move upwards from $2.44 \mathrm{GHz}$ to $2.73 \mathrm{GHz}$ with the decreases of $C_{F}$ from $100 \mathrm{pF}$ to $4.7 \mathrm{pF}$, while TZ near the first passband edge also moves upwards from $2.12 \mathrm{GHz}$ to $2.42 \mathrm{GHz}$ for sharp skirt. For the other three passband edges and TZs for sharp selectivity, they are unaltered.

Similar to the first passband edge, the second and third ones also can be independently tunable by controlling the capacitors of $C_{S}$ and $C_{T}$. In Figure $9 \mathrm{~b}, \mathrm{c}$, the simulated and measured results under Case $\mathrm{C}\left(C_{F}=C_{T}=C_{S}=100 \mathrm{pF}\right)$ and $\mathrm{D}\left(C_{F}=100 \mathrm{pF}, C_{S}=2.2 \mathrm{pF}\right.$, and $\left.C_{T}=2.4 \mathrm{pF}\right)$ are shown, respectively. Compared with Case $\mathrm{A}$ and $\mathrm{C}$, it can be obtained that the second passband edge with matching better than $10 \mathrm{~dB}$ moves downwards from $3.19 \mathrm{GHz}$ to $2.96 \mathrm{GHz}$ as $C_{T}$ increases from $2.4 \mathrm{pF}$ to $100 \mathrm{pF}$, while TZ near the second passband moves downwards from $3.34 \mathrm{GHz}$ to $3.26 \mathrm{GHz}$ for sharp skirt. By comparing Case $\mathrm{A}$ and $\mathrm{D}$, it is obvious that the third passband edge with matching better than $10.0 \mathrm{~dB}$ will move upwards from $3.73 \mathrm{GHz}$ to $3.89 \mathrm{GHz}$ with the decrease in $C_{T}$ from $100 \mathrm{pF}$ to $2.2 \mathrm{pF}$, while TZs near the third passband are shifted from $3.59 \mathrm{GHz}$ to $3.62 \mathrm{GHz}$ for sharp skirt. For the rest of the passband edges and other TZs, they are unaltered. Hence, the three independently tunable passband edges can be validated.

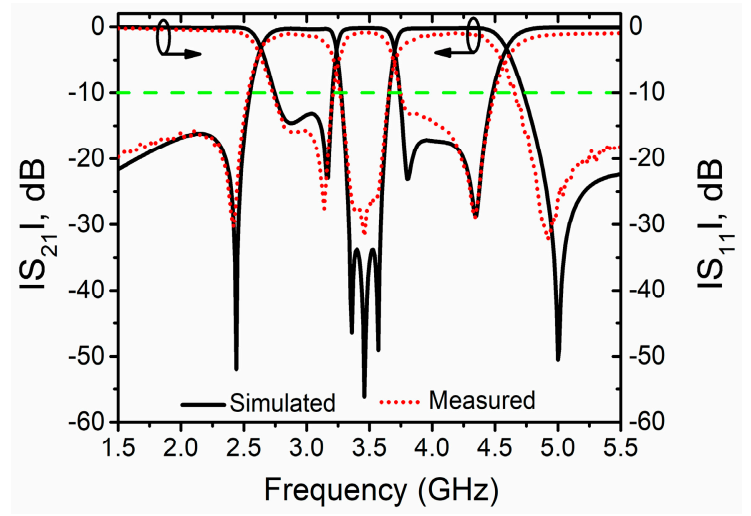

(a)

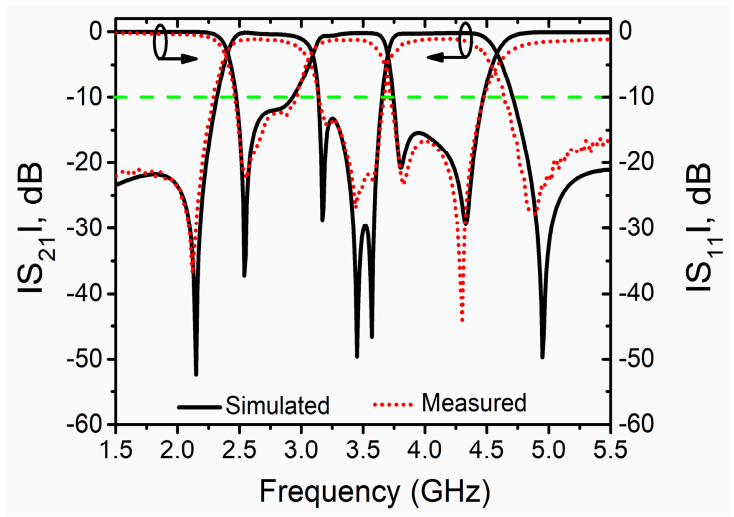

(b)

Figure 9. Cont. 


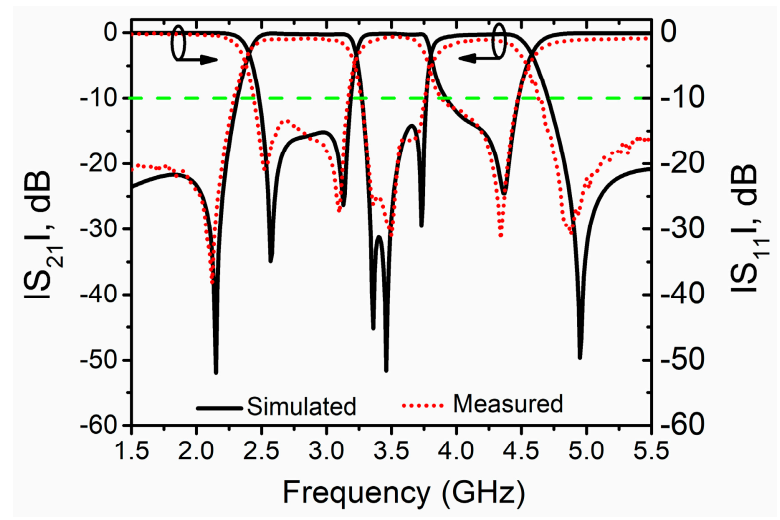

(c)

Figure 9. Filter responses with respect to (a) Case B: $C_{F}=4.7 \mathrm{pF}, C_{S}=2.4 \mathrm{pF}, C_{T}=100 \mathrm{pF}$; (b) Case C: $C_{F}=100 \mathrm{pF}, C_{S}=100 \mathrm{pF}, C_{T}=100 \mathrm{pF}$; (c) Case D: $C_{F}=100 \mathrm{pF}, C_{S}=2.4 \mathrm{pF}, C_{T}=2.2 \mathrm{pF}$.

\subsection{Independently Tunable Center Frequency of Lower Passband with Fixed Absolute Bandwidth}

As the first and second passband edges can be independently tunable by changing the capacitors of $C_{F}$ and $C_{S}$, respectively, it is apparent that the center frequency of lower passband also can be independently tunable by suitably selecting these two capacitors, while the corresponding absolute bandwidth is fixed. This reconfigurable property is validated by comparing Case B and C. By gradually decreasing $C_{F}$ from $100.0 \mathrm{pF}$ to $2.4 \mathrm{pF}$ and suitably choosing the capacitor of $C_{S}$, the center frequency of lower passband can be continuously shifted from $2.71 \mathrm{GHz}$ to $2.97 \mathrm{GHz}$, while the absolute bandwidth with matching better than $10.0 \mathrm{~dB}$ is about $0.49 \mathrm{GHz}$. For the upper passband, it is fixed. Hence, the fractional tuning range of lower passband is $9.6 \%$, and the corresponding constant FBW is $18.1 \%$.

One thing should be noted: only two reported IEEE journal papers concern the tunable center frequencies of dual-band BPFs with constant absolute bandwidths, which are presented in [9] and [17]. Unfortunately, their constant FBWs are narrow and no more than 9.3\%. Hence, the proposed design should be beneficial to exploration of other tunable-center-frequency DWB BPFs with constant absolute bandwidths.

\subsection{Independently Tunable Bandwidth of Lower Passband with Fixed Center Frequency}

Among the reported tunable DWB BPFs, there is no report of the independently tunable bandwidth of lower passband with constant center frequency, which will restrict the development of telecommunication. In this part, this desired reconfigurable property is implemented.

As the first passband edge will move downwards with the increase in $C_{F}$, and the second one will move upwards with the decrease in $C_{S}$, the bandwidth of lower passband can be tunable in continue manners by gradually increasing $C_{F}$ and decreasing $C_{S}$ simultaneously, while the corresponding center frequency and upper passband is unchanged. This reconfigurable property can be validated by comparing Case A and $\mathrm{E}\left(C_{F}=4.8 \mathrm{pF}, \mathrm{C}_{S}=6.2 \mathrm{pF}, \mathrm{C}_{T}=100 \mathrm{pF}\right)$, whose simulated and measured results are depicted in Figure 10. By suitably decreasing $C_{F}$ from $100 \mathrm{pF}$ to $4.8 \mathrm{pF}$ and increasing $C_{S}$ from $2.4 \mathrm{pF}$ to $6.2 \mathrm{pF}$, the FBW of the lower passband is varied from $26.6 \%$ to $9.9 \%$, and the corresponding center frequency is about $2.83 \mathrm{GHz}$. Meanwhile, TZs near the first and second passband edges are shifted from $2.12 \mathrm{GHz}$ and $2.40 \mathrm{GHz}$ to $3.34 \mathrm{GHz}$ and $3.29 \mathrm{GHz}$, respectively. Furthermore, the upper passband is unaltered. Hence, DWB BPF with independently tunable bandwidth and fixed center frequency of lower passband can be designed. 


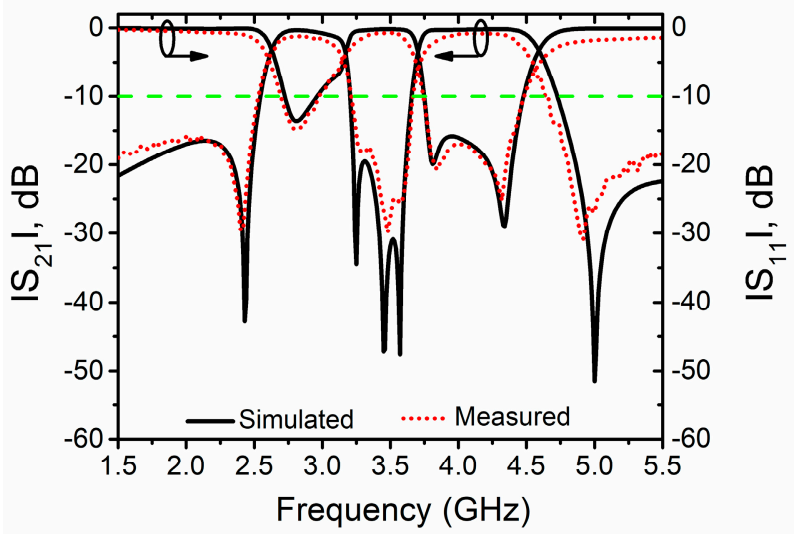

Figure 10. Filter responses of Case $E\left(C_{F}=4.8 \mathrm{pF}, C_{S}=6.2 \mathrm{pF}, C_{T}=100 \mathrm{pF}\right)$.

\subsection{Independently Switchable Lower Passband}

Although the switchable dual-band BPFs have been studied extensively, their corresponding passbands are relatively small, as presented in [15-17]. In other words, there is no DWB BPF with independently switchable passbands reported. Therefore, the successful design of DWB BPFs with switchable bandwidth should be beneficial to the modern telecommunication.

As mentioned in Case A with $C_{F}=C_{T}=100 \mathrm{pF}$, and $C_{S}=2.4 \mathrm{pF}$, there are two passbands with FBWs of $26.6 \%$ and $17.8 \%$. Then, the lower passband will be changed into a stopband under the condition of Case F with $C_{F}=1.5 \mathrm{pF}, C_{S}=100 \mathrm{pF}$, and $C_{T}=100 \mathrm{pF}$, while the upper one is almost fixed, as depicted in Figure 11. Thus, the lower passband can be independently switchable.

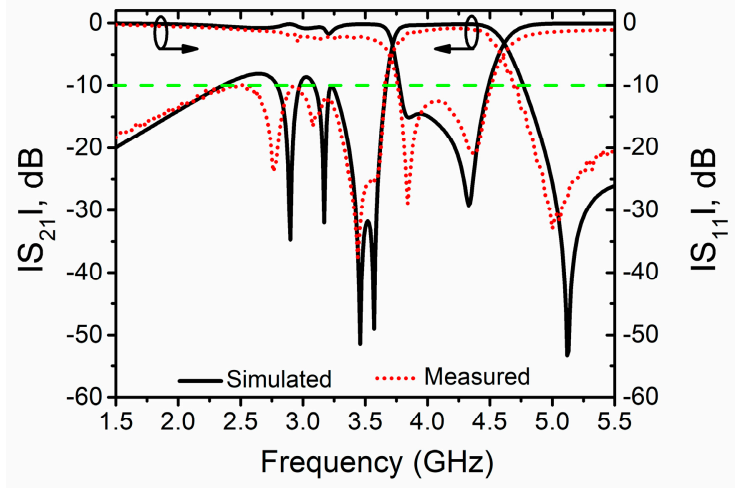

Figure 11. Filter responses of Case $F\left(C_{F}=1.5 \mathrm{pF}, C_{S}=100 \mathrm{pF}, C_{T}=100 \mathrm{pF}\right)$.

\subsection{Independently Tunable First Passband Edge of SWB BPF}

Considering that the lower passband will be changed into a stopband by selecting the suitable capacitors of $C_{F}$ and $C_{S}$, and the third passband edge can be independently tunable by controlling the capacitor of $C_{T}$, SWB BPFs with tunable bandwidth can be designed based on this novel topology. This is verified by comparing Case F and G. As shown in Figures 11 and 12, the first passband edge of SWB BPFs is shifted from $3.76 \mathrm{GHz}$ to $4.07 \mathrm{GHz}$ with the decrease in $C_{T}$ from $100 \mathrm{pF}$ to $1.4 \mathrm{pF}$, while the other one is fixed about $4.50 \mathrm{GHz}$. In addition, TZ near the first passband edge of SWB BPFs is varied from $3.58 \mathrm{GHz}$ to $3.76 \mathrm{GHz}$. Thus, a SWB BPF with tunable-bandwidth range of $7.5 \%$ can be designed.

In Figure 13, the photograph of the fabricated filter is given. To vividly demonstrate this topology, the simulated and measured results under different cases are listed in Table 1. One thing should be noted - the insertion loss in the passband is no more than $1.4 \mathrm{~dB}$ for all the cases, while the group delay is less than $2.35 \mathrm{~ns}$. To demonstrate the advantages of this design, a comparison with some previous works is presented in Table 2. Obviously, the proposed work can not only be used to 
design SWB BPFs with tunable bandwidth, but also DWB BPFs with tunable center frequency, tunable bandwidth, and switchable passband. Considering the new reconfigurable properties, i.e., tunable bandwidth of lower passband with fixed absolute center frequency, the proposed work can reduce the design complicity and circuit size of multi-functional wireless communication systems effectively and conveniently.

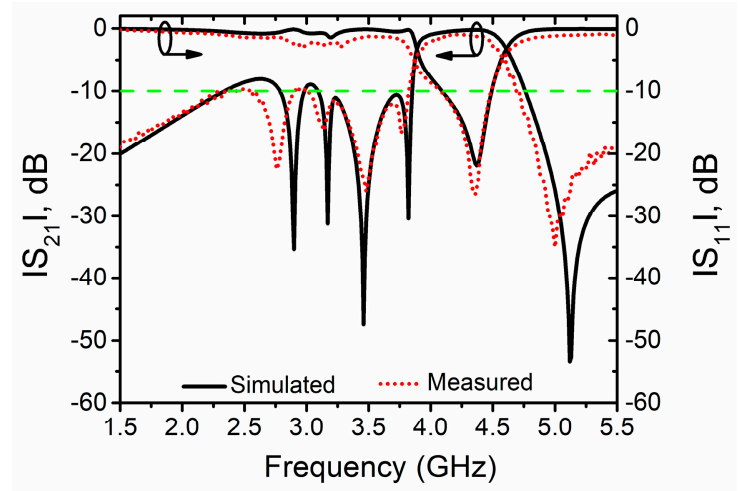

Figure 12. Filter responses of Case $G\left(C_{F}=1.5 \mathrm{pF}, C_{S}=100 \mathrm{pF}, C_{T}=1.4 \mathrm{pF}\right)$.

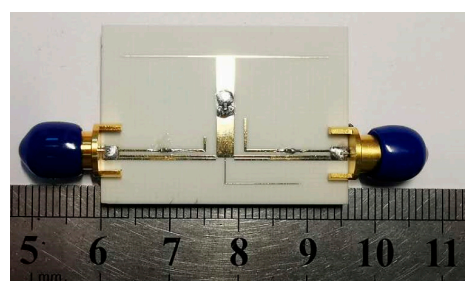

Figure 13. The photograph of the fabricated filter.

Table 1. Simulated and measured results under different cases.

\begin{tabular}{|c|c|c|c|c|c|c|c|c|c|c|c|}
\hline & & \multicolumn{2}{|c|}{ Lower Passband } & \multicolumn{2}{|c|}{ Upper Passband } & & & \multicolumn{2}{|c|}{ Lower Passband } & \multicolumn{2}{|c|}{ Upper Passband } \\
\hline & & First $^{1}$ & Second $^{2}$ & Third $^{3}$ & Fourth $^{4}$ & & & First $^{1}$ & Second $^{2}$ & Third $^{3}$ & Fourth ${ }^{4}$ \\
\hline \multirow{2}{*}{ Case A } & Simulated & $2.48 \mathrm{GHz}$ & $3.20 \mathrm{GHz}$ & $3.74 \mathrm{GHz}$ & $4.48 \mathrm{GHz}$ & \multirow{2}{*}{ Case E } & Simulated & $2.73 \mathrm{GHz}$ & $2.96 \mathrm{GHz}$ & $3.75 \mathrm{GHz}$ & $4.48 \mathrm{GHz}$ \\
\hline & Measured & $2.44 \mathrm{GHz}$ & $3.19 \mathrm{GHz}$ & $3.73 \mathrm{GHz}$ & $4.46 \mathrm{GHz}$ & & Measured & $2.70 \mathrm{GHz}$ & $2.98 \mathrm{GHz}$ & $3.74 \mathrm{GHz}$ & $4.48 \mathrm{GHz}$ \\
\hline \multirow{2}{*}{ Case B } & Simulated & $2.75 \mathrm{GHz}$ & $3.21 \mathrm{GHz}$ & $3.74 \mathrm{GHz}$ & $4.48 \mathrm{GHz}$ & \multirow{2}{*}{ Case F } & Simulated & N/A & N/A & $3.78 \mathrm{GHz}$ & $4.49 \mathrm{GHz}$ \\
\hline & Measured & $2.73 \mathrm{GHz}$ & $3.21 \mathrm{GHz}$ & $3.75 \mathrm{GHz}$ & $4.49 \mathrm{GHz}$ & & Measured & N/A & N/A & $3.76 \mathrm{GHz}$ & $4.51 \mathrm{GHz}$ \\
\hline Case C & Simulated & $2.48 \mathrm{GHz}$ & $2.93 \mathrm{GHz}$ & $3.75 \mathrm{GHz}$ & $4.47 \mathrm{GHz}$ & Case G & Simulated & N/A & N/A & $4.09 \mathrm{GHz}$ & $4.49 \mathrm{GHz}$ \\
\hline \multirow{2}{*}{ Case D } & Simulated & $2.48 \mathrm{GHz}$ & $3.19 \mathrm{GHz}$ & $3.92 \mathrm{GHz}$ & $4.48 \mathrm{GHz}$ & & & & & & \\
\hline & Measured & $2.44 \mathrm{GHz}$ & $3.17 \mathrm{GHz}$ & $3.89 \mathrm{GHz}$ & $4.47 \mathrm{GHz}$ & & & & & & \\
\hline
\end{tabular}

First $^{1}$ : First passband edge with matching better than $10.0 \mathrm{~dB}$; Second ${ }^{2}$ : Second passband edge with matching better than $10.0 \mathrm{~dB}$; Third ${ }^{3}$ : Third passband edge with matching better than $10.0 \mathrm{~dB}$; Fourth ${ }^{4}$ : Fourth passband edge with matching better than $10.0 \mathrm{~dB}$.

Table 2. Comparison with previous works.

\begin{tabular}{|c|c|c|c|c|c|c|c|c|c|}
\hline & \multirow{2}{*}{$\begin{array}{c}\text { SWB BPFs } \\
\text { TBW }^{1}\end{array}$} & \multicolumn{3}{|c|}{ DWB BPFs } & & \multirow{2}{*}{$\frac{\text { SWB BPFs }}{\text { TBW }^{1}}$} & \multicolumn{3}{|c|}{ DWB BPFs } \\
\hline & & TCF $^{2}$ & TBW $^{1}$ & SPB $^{3}$ & & & TCF $^{2}$ & TBW $^{1}$ & $\mathrm{SPB}^{3}$ \\
\hline [9] & No & Yes & No & No & Filter B in [17] & No & Yes & No & Yes \\
\hline [10] & No & Yes & No & No & Filter B in [20] & No & No & Yes & No \\
\hline [12] & Yes & No & No & No & Filter B in [22] & No & Yes & Yes & No \\
\hline [13] & Yes & No & No & No & This work & Yes & Yes & Yes & Yes \\
\hline [16] & No & No & No & Yes & & & & & \\
\hline
\end{tabular}

$\mathrm{TBW}^{1}$ : tunable bandwidth; $\mathrm{TCF}^{2}$ : tunable center frequency; $\mathrm{SPB}^{3}$ : switchable passband. 


\section{Conclusions}

In this paper, a novel topology is presented for the design of SWB/DWB BPFs with different reconfigurable properties. This design is based on a dual-wideband passive filtering structure with three TPs in each passband and five TZs in the stopbands, and three capacitors are used as the tuning elements. By controlling the inserted capacitors, it is found that SWB BPFs with tunable bandwidth, and DWB BPFs with tunable center frequency, tunable bandwidths, and switchable passband, can be achieved simultaneously. For verification, a prototype with different capacitors is designed and fabricated. Obviously, the simulated and measured results are in good agreement. Considering that the proposed design owns novel and masses of reconfigurable properties, it is anticipated that this filter can be broadly used in the modern multi-functional telecommunication systems.

Author Contributions: Conceptualization, X.B. and T.Y.; data curation, K.H. and Z.Z.; formal analysis, X.B. and W.H.; funding acquisition, T.Y. and W.H.; investigation, S.G. and Z.Z.; methodology, K.H. and T.Y.; resources, Z.Z. and T.Y.; software, T.Y. and W.H.; supervision, T.Y. and W.H.; validation, S.G. and K.H.; writing-original draft, S.G. and X.B.; writing-review and editing, X.B. All authors have read and agreed to the published version of the manuscript.

Funding: This work is supported in part by the Natural Science Foundation of China under Grant 61801298; the Guangdong Provincial Department of Science and Technology, China, under Project No. 2020B1212030002; the Foundation of Shenzhen under Grants JCYJ20170302142545828 and JCYJ20180305124721920 and No. KQTD 20180412181337494; in part by the National Key Research and Development Program, China, under Subject No.2019YFF0216602; and the Foundation of Shenzhen University under Grants 2016057, 2019119, and 2019120.

Conflicts of Interest: The authors declare no conflict of interest.

\section{References}

1. Hou, Z.Y.; Liu, C.G.; Zhang, B.; Song, R.G.; Wu, Z.P.; Zhang, J.W.; He, D.P. Dual-/Tri-Wideband Bandpass Filter with High Selectivity and Adjustable Passband for 5G Mid-Band Mobile Communications. Electronics 2020, 9, 205. [CrossRef]

2. Yang, L.; Gómez-García, R.; Muñoz-Ferreras, J.-M.; Zhang, R.-Q.; Peroulis, D.; Zhu, L. Multilayered Reflectionless Wideband Bandpass Filters With Shunt/In-Series Resistively Terminated Microstrip Lines. IEEE Trans. Microw. Theory Tech. 2019, 68, 877-893. [CrossRef]

3. Lalbakhsh, A.; Alizadeh, A.M.; Ghaderi, A.; Golestanifar, A.; Mohamadzade, B.; Jamshidi, M.; Mandal, K.; Mohyuddin, W. A Design of a Dual-Band Bandpass Filter Based on Modal Analysis for Modern Communication Systems. Electronics 2020, 9, 1770. [CrossRef]

4. Bi, X.K.; Zhang, X.; Huang, G.; Tao, Y. Compact Microstrip NWB/DWB BPFs With Controllable Isolation Bandwidth for Interference Rejection. IEEE Access 2019, 7, 49169-49176. [CrossRef]

5. Bi, X.K.; Zhang, X.; Wang, S.W.; Yuan, T.; Guo, S.H. Design of Equal-Ripple Dual-Wideband Bandpass Filter With Minimum Design Parameters Based on Cross-Shaped Resonator. IEEE Trans. Circuits Syst. II Express Briefs 2020, 67, 1780-1784. [CrossRef]

6. Mostrah, A.E.; Muller, A.; Favennec, J.-F.; Potelon, B.; Manchec, A.; Ruis, E.; Quendo, C.; Clavet, Y.; Doukhan, F.; Le Nezet, J. An RF-MEMS-Based Digitally Tunable SIW Filter in X-Band for Communication Satellite Application. Appl. Sci. 2019, 9, 1838. [CrossRef]

7. Ohira, M.; Hashimoto, S.M.; Ma, Z.-W.; Wang, X.L. Coupling-Matrix-Based Systematic Design of Single-DC-Bias-Controlled Microstrip Higher Order Tunable Bandpass Filters With Constant Absolute Bandwidth and Transmission Zeros. IEEE Trans. Microw. Theory Tech. 2018, 67, 118-128. [CrossRef]

8. Lu, D.; Yu, M.; Barker, N.S.; Li, Z.-Y.; Li, W.; Tang, X.-H. Advanced Synthesis of Wide-Tuning-Range Frequency-Adaptive Bandpass Filter With Constant Absolute Bandwidth. IEEE Trans. Microw. Theory Tech. 2019, 67, 4362-4375. [CrossRef]

9. Khani, S.; Mousavi, S.M.H.; Danaie, M.; Rezaei, P. Tunable compact microstrip dual-band bandpass filter with tapered resonators. Microw. Opt. Technol. Lett. 2018, 60, 1256-1261. [CrossRef]

10. Xu, J.; Wu, W.; Wei, G. Novel Dual-Band Bandpass Filter and Reconfigurable Filters Using Lumped-Element Dual-Resonance Resonators. IEEE Trans. Microw. Theory Tech. 2016, 64, 1496-1507. [CrossRef] 
11. Bi, X.-K.; Cheng, T.; Cheong, P.; Ho, S.-K.; Tam, K.-W. Wideband bandpass filters with reconfigurable bandwidth and fixed notch bands based on terminated cross-shaped resonator. IET Microw. Antennas Propag. 2019, 13, 796-803. [CrossRef]

12. Zhang, B.; Li, S.-S.; Huang, J.-M. High performance tunable bandpass filter with separately reconfigurable passband edges. Microw. Opt. Technol. Lett. 2015, 57, 1111-1113. [CrossRef]

13. Wang, X.M.; Bi, X.-K.; Guo, S.H.; He, J.; Li, C.L.; Liu, J.J.; Hu, G.Q.; Ma, G.J.; Xu, Z.-T. Synthesis Design of Equal-Ripple and Quasi-Elliptic Wideband BPFs with Independently Reconfigurable Lower Passband Edge. IEEE Access 2020, 8, 76856-76866. [CrossRef]

14. Bi, X.K.; Zhang, X.; Wang, S.W.; Guo, S.H.; Yuan, T. Synthesis Design of Chebyshev Wideband Band-Pass Filters With Independently Reconfigurable Lower Passband Edge. IEEE Trans. Circuits Syst. II Express Briefs 2020, 67, 2948-2952. [CrossRef]

15. Chuang, M.-L.; Wu, M.-T. Switchable Dual-Band Filter with Common Quarter-Wavelength Resonators. IEEE Trans. Circuits Syst. II Express Briefs 2015, 62, 347-351. [CrossRef]

16. Lee, V.; Lee, S.; Sis, S.A.; Mortazawi, A. Intrinsically Switchable Frequency Reconfigurable Barium Strontium Titanate Resonators and Filters. IEEE Trans. Microw. Theory Tech. 2017, 65, 3221-3229. [CrossRef]

17. Lu, D.; Tang, X.H.; Barker, N.S.; Feng, Y.K. Single-Band and Switchable Dual-/Single-Band Tunable BPFs With Predefined Tuning Range, Bandwidth, and Selectivity. IEEE Trans. Microw. Theory Tech. 2017, 66, 1215-1227. [CrossRef]

18. Chaudhary, G.; Jeong, Y.; Lim, J. Dual-Band Bandpass Filter with Independently Tunable Center Frequency and Bandwidths. IEEE Trans. Microw. Theory Tech. 2012, 61, 107-116. [CrossRef]

19. Wu, Y.; Nan, L.; Jiao, L.; Wang, W.; Liu, Y. Dual-band coupled-line bandpass filter with independently tunable bandwidths. China Commun. 2016, 13, 60-64. [CrossRef]

20. Kumar, N.; Singh, Y.K. RF-MEMS-Based Bandpass-to-Bandstop Switchable Single- and Dual-Band Filters with Variable FBW and Reconfigurable Selectivity. IEEE Trans. Microw. Theory Tech. 2017, 65, 3824-3837. [CrossRef]

21. Bi, X.-K.; Cheng, T.; Cheong, P.; Ho, S.-K.; Tam, K.-W. Design of Dual-Band Bandpass Filters with Fixed and Reconfigurable Bandwidths Based on Terminated Cross-Shaped Resonator. IEEE Trans. Circuits Syst. II Express Briefs 2018, 66, 317-321. [CrossRef]

22. Simpson, D.J.; Gómez-García, R.; Psychogiou, D. Single-/Multi-Band Bandpass Filters and Duplexers with Fully Reconfigurable Transfer-Function Characteristics. IEEE Trans. Microw. Theory Tech. 2019, 67, 1854-1869. [CrossRef]

23. Bi, X.K.; Zhang, X.; Wang, S.W.; Guo, S.H.; Yuan, T. Reconfigurable-Bandwidth DWB BPF with Fixed Operation Frequency and Controllable Stopband. IEEE Trans. Circuits Syst. II Express Briefs 2020. to be published. [CrossRef]

Publisher's Note: MDPI stays neutral with regard to jurisdictional claims in published maps and institutional affiliations.

(C) 2020 by the authors. Licensee MDPI, Basel, Switzerland. This article is an open access article distributed under the terms and conditions of the Creative Commons Attribution (CC BY) license (http://creativecommons.org/licenses/by/4.0/). 